\title{
Verification benchmark for a single-phase flow hydro - mechanical model comparison between COMSOL Multiphysics and $\mathrm{DuMu}^{\mathrm{x}}$
}

\author{
Dejian Zhou ${ }^{1 *}$, Alexandru Tatomir ${ }^{1,2}$, Ingrid Tomac ${ }^{3}$, Martin Sauter ${ }^{1}$ \\ ${ }^{1}$ Department of Applied Geology, 37073, Göttingen, Germany \\ ${ }^{2}$ Department of Earth Sciences, Uppsala University, 75236 Uppsala, Sweden \\ ${ }^{3}$ Structural Engineering Department, University of California San Diego, 92093 San Diego, CA, U.S.A.
}

\begin{abstract}
Numerical modelling of hydromechanical processes in geological environments has become an invaluable tool in understanding and predicting system behaviour. However, due to the different algorithms and numerical schemes implemented in the different models, model reliability may vary considerably. Modelling of single- and multi-phase flow in porous media has been widely employed in various engineering applications such as geological disposal of nuclear waste, geological storage of carbon dioxide, hightemperature geothermal systems, or hydraulic fracturing for shale gas exploitation. Coupled hydromechanical (H-M) processes play a key role in the prediction of the behaviour of geological reservoirs during their development and testing operations. In this paper, we present a benchmark test on a single-phase flow problem in a hydrogeological reservoir with 5 horizontal layers of different properties. The aim is to compare two hydromechanical (H-M) models that use a vertex-centred finite-volume discretization and a finite element discretization. The first model is constructed with the free-open source simulator $\mathrm{DuMu}^{\mathrm{X}}$, and the second with the commercial software COMSOL Multiphysics. The verification study suggests general confidence in the model reliability, but also highlights and discusses several areas of discrepancies between two models.
\end{abstract}

\section{Introduction}

Hydrogeological problems are generally difficult to study directly because the subsurface structures are not accessible to direct studies and characterisation. Thus, modelling is a widely utilized tool for understanding the influence of complexity in geometry, heterogeneity in the respective properties (mechanical, hydraulic, etc.) as well as the effect of process coupling, such as thermo-hydromechanical-chemical (THMC) processes. Various numerical simulators such as TOUGH-FLAC (Rutqvist, 2013), CODE-BRIGHT (UPC, 2002) and $\mathrm{DuMu}^{\mathrm{X}}$ (Flemisch et al. 2011) etc. were developed by different groups around the world, contributing to the enrichment of the field of hydrogeological modelling. However, due to different approaches in solving the respective differential equations, programming languages, and the design algorithms of the different models, differences between modelling results can be expected for the same problem. Several verification benchmarking initiatives for simulators of flow and transport in (fractured) porous media are reported in the literature, e.g.., (Ebigbo et al. 2007; Class et al. 2009; Flemisch et al. 2018; Berre et al. 2018; Berre et al. 2020a; Berre et al. 2020b).

This paper presents the results of a benchmarking study on the hydro-mechanical (H-M) effects induced by a single-phase fluid injection into a fully saturated multi- layered geological system. In this sense, the same problem is implemented in two numerical simulators, i.e., COMSOL Multiphysics and $\mathrm{DuMu}^{\mathrm{X}}$ and the results are compared based on the state variables overpressure, vertical displacement and change in effective stress. $\mathrm{DuMu}^{\mathrm{X}}$ is an academic code which is available free of charge and public-domain. The hydro-mechanical model has been originally developed by Darcis (2013) and (Beck 2019). Geomechanical studies conducted with $\mathrm{DuMu}^{\mathrm{X}}$ were performed in (Darcis 2013; Tatomir et al. 2016; Beck et al. 2016; Beck 2019; Beck and Class 2019; Vilarrasa et al. 2020). A good overview of the software's application in the context of geological storage of $\mathrm{CO}_{2}$ is done by (Tatomir et al. 2019). Understanding of the H-M effects is relevant in hydraulic fracturing operations, however, previous studies using $\operatorname{DuMu}^{\mathrm{X}}$ (Gläser et al. 2016; Tatomir et al. 2018; Schout et al. 2020) do not address these. The HM model implemented in $\mathrm{DuMu}^{\mathrm{X}}$ uses the box method for spatial discretization and a fully implicit Euler scheme for the time discretization (Darcis 2013).

COMSOL Multiphysics is a commercial software known for a flexible implementation environment and a capacity to couple different physical processes. The spatial discretization is based on the finite element method. Recently, COMSOL was widely applied in HM

\footnotetext{
* Corresponding author: dejian.zhou@geo.uni-goettingen.de
} 
modelling implementation (e.g, Holzbecher 2013; Tony et al., 2008; Xiang et al., 2018).

In contrast to the fully coupled $\mathrm{DuMu}^{\mathrm{X}}$ model, COMSOL model is sequentially coupled. First, at one time-step, the flow solution is calculated and then the effective pore pressure is used for the calculation of stresses and mechanical deformations.

\section{Model setup}

The benchmark problem, proposed initially by (Vilarrasa et al. 2020) considers flow and mechanical processes in a porous geological material perturbed by the injection of water into the multi-layered system. The mechanical stress-strain relationships assume linear elasticity, and the problem is isothermal. The reservoir and the other layers in the domain, i.e. cap-rock, under-burden, the upper aquifer and the basal aquifer (

The comparison of the two simulators is further provided as breakthrough curves (plots of parameter of interest per time) at different observation points, and as plots of parameter of interest over horizontal planes at different depth.

) are assumed to be homogenous and isotropic with respect to their hydraulic and mechanical properties. Water is injected into the initially fully saturated reservoir located between depths of $1500 \mathrm{~m}$ and $1530 \mathrm{~m}$, with an injection rate of $30 \mathrm{~kg} / \mathrm{s}$. The injected water temperature is $60^{\circ} \mathrm{C}$ i.e. the same temperature as that in the reservoir and the entire domain. The reservoir and surrounding geological structures are assumed to be horizontal. The simulated domain is $1000 \mathrm{~m}$ below the ground and the initial hydrostatic pressure on the top of the domain is 10 $\mathrm{MPa}$, the densities of reservoir and surrounding rocks are set to a constant $2400 \mathrm{~kg} / \mathrm{m}^{3}$, which means the lithostatic pressure imposed by the rocks above the domain is 24 MPa.

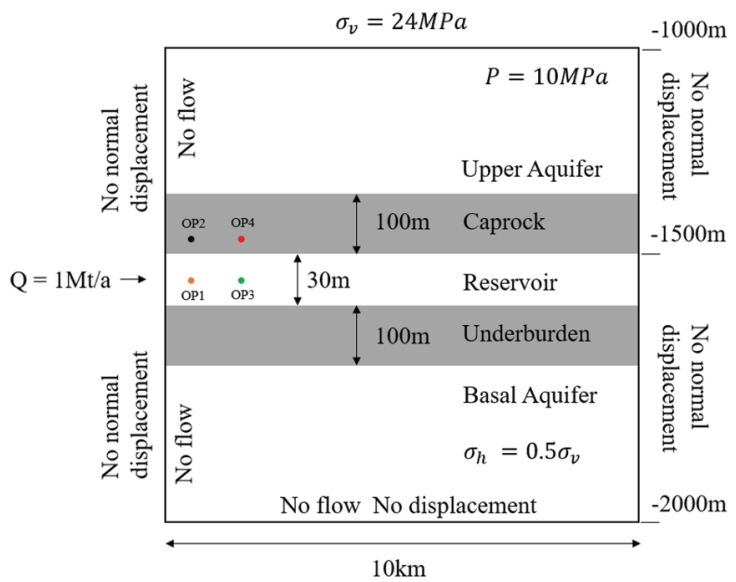

Figure 1 Schematic of the geometry, initial and boundary conditions of the model (Vilarrasa et al. 2020)

The reservoir is bound by two impermeable layers, i.e. caprock and underburden. Since in reservoir application studies the assessment of caprock integrity is of higher importance than potential H-M induced changes in the reservoir formation, this model includes two more layers above the caprock and below the underburden. The initial water pressure is hydrostatic and maintains a constant pressure at the outer boundary, placed at $10 \mathrm{~km}$ distance from the injection well. The initial stress field coincides with the vertical effective stress distribution i.e. 24 $\mathrm{MPa} / \mathrm{km}$ and the horizontal effective stresses equals 0.5 times the vertical effective stress (Rutqvist, 2013). A constant stress equal to the overburden is applied at the upper boundary. The other boundaries have no displacement perpendicular to the boundary.

The parameters used in the model and detailed geometry are presented in Table $\mathbf{1}$ and

The comparison of the two simulators is further provided as breakthrough curves (plots of parameter of interest per time) at different observation points, and as plots of parameter of interest over horizontal planes at different depth.

Table 1 Material properties of the layers in the models

\begin{tabular}{|c|c|c|c|c|c|}
\hline Property & Reservoir & $\begin{array}{c}\text { Cap- } \\
\text { rock }\end{array}$ & $\begin{array}{c}\text { Under- } \\
\text { burden }\end{array}$ & $\begin{array}{c}\text { Upper } \\
\text { aquifer }\end{array}$ & $\begin{array}{c}\text { Basal } \\
\text { aquifer }\end{array}$ \\
\hline $\begin{array}{c}\text { Permeability } \\
{\left[\mathrm{m}^{2}\right]}\end{array}$ & $1.23 \cdot 10^{-13}$ & $10^{-17}$ & $10^{-18}$ & $10^{-13}$ & $10^{-14}$ \\
\hline Porosity [-] & 0.2 & 0.01 & 0.01 & 0.15 & 0.1 \\
\hline $\begin{array}{c}\text { Young's } \\
\text { Modulus } \\
{[\mathrm{GPa}]}\end{array}$ & 15 & 5 & 5 & 10 & 20 \\
\hline $\begin{array}{c}\text { Poisson } \\
\text { Ratio [-] }\end{array}$ & 0.3 & 0.3 & 0.3 & 0.3 & 0.3 \\
\hline
\end{tabular}

The hydraulic and mechanical models are coupled, the coupling is done with through the pore pressure and the mechanical response to stress and pressure changes leads to changes in porosity and intrinsic permeability, for $\mathrm{DuMu}^{\mathrm{x}}$ and COMSOL, the correlations are the same, shown below:

$$
\begin{aligned}
\phi_{e f f} & =1-(1-\phi) e^{-\varepsilon_{v}} \\
K_{e f f} & =K\left(\frac{\phi_{e f f}}{\phi}\right)^{n}
\end{aligned}
$$

in which $\varepsilon_{v}$ is the volumetric strain, which is equal to the sum of the axial strains, $\phi$ is porosity, $K$ is the intrinsic permeability, the subscript eff stand for effective and indicates the mechanics- calibrated value, $n$ is the empirical constant set to 15 in this model, e.g., the same as in Beck et al. (2016) and Figueiredo et al. (2020). With the effective porosity and intrinsic permeability, the mass conservation equation can be written:

$$
\begin{gathered}
\phi_{e f f} X_{f} \frac{d p}{d t}+\nabla \cdot(\rho \boldsymbol{u})-Q_{s k}=0 \\
\boldsymbol{u}=-\frac{K_{e f f}}{\mu}(\nabla p-\rho \mathbf{g})
\end{gathered}
$$

where $X_{f}$ is the compressibility of water, $Q_{s k}$ is the source and sink term, $\boldsymbol{u}$ is the Darcy velocity, and $\mu$ and $\rho$ are the dynamic viscosity and density of water, respectively, $t$ is 
time, $\nabla p$ is the gradient of hydraulic head, and $\mathbf{g}$, the gravitational acceleration.

The correlation between strain $\varepsilon_{i j}$ and pore water pressure $p$ is presented below:

$$
\begin{array}{cc}
\sigma^{\prime}=\sigma-\alpha p & \\
\varepsilon_{i j}=\frac{\sigma_{i j}-\alpha p \delta_{i j}}{E_{i j}} & i, j=x, y \\
\varepsilon_{i j}=\frac{1}{2}\left(\frac{\partial u_{i}}{\partial j}+\frac{\partial u_{j}}{\partial \mathrm{i}}\right) & i, j=x, y
\end{array}
$$

where $\sigma^{\prime}$ is the Biot effective stress in porous media, $\alpha$ is the Biot coefficient, ranged 0 (completely dry) to 1 (fully water saturated), $p$ is the water pressure, $\delta_{i j}$ is Kronecker delta, means if $i=j, \delta_{i j}=1$, else, $\delta_{i j}=0$, here it donates that the water pressure only works on normal stress and axial strain $(i=j)$, for shear stress and shear strain $(i \neq$ $j$ ), water pressure is zero, $\varepsilon_{i j}$ and $E_{i j}$ are the strain and elastic modulus, respectively, $i$ and $j$ donate the direction of axis, $u_{i}$ and $u_{j}$ are the displacement along the direction $i$ and $j$.

A detailed description of the mathematical model and the numerical implementation in the $\mathrm{DuMu}^{\mathrm{X}}$ are given in (Darcis 2013; Beck et al. 2016; Beck 2019) and the implementation in COMSOL Multiphysics follows the description of (Holzbecher 2013).

The comparison of the two simulators is further provided as breakthrough curves (plots of parameter of interest per time) at different observation points, and as plots of parameter of interest over horizontal planes at different depth.

\section{Results}

\subsection{Overpressure}

The comparison between the two sets of model results, essentially temporal and spatial distribution of water overpressure (pressure difference between initial status and injection) is the essential part of the benchmark study. The fully saturated system reached equilibrium before actual simulation commenced, the correlation between initial strain $\varepsilon_{i, i j}$ and stress $\sigma_{i, i j}$ is shown below:

$$
\varepsilon_{i, i j}=\frac{\sigma_{i, i j}-\alpha P_{i n i t}}{E_{i j}}
$$

where the $\sigma_{i, i j}$ is the stress from rock gravity and $P_{\text {init }}$ is steady pore water pressure, during the injection:

$$
\varepsilon_{i j}=\frac{\sigma_{i, i j}-\alpha P}{E_{i j}}=\frac{\sigma_{i, i j}-\alpha \text { Pinit }-\alpha P_{\text {over }}}{E_{i j}}=\varepsilon_{i, i j}+\Delta \varepsilon_{i j}
$$

where $P_{\text {over }}$ is the water overpressure, calculated by subtracting the initial water pressure at a point location, before injection start, from the water pressure at a calculation time $t, \Delta \varepsilon_{i j}$ is the additional strain due to the injection. In $\mathrm{DuMu}^{\mathrm{X}}$, the initial equilibrium condition is set to be the reference, i.e. $\varepsilon_{i, i j}=0$, since the system is fully saturated by water $(\alpha=1)$. As shown in Eq. (7) and
(9), $p_{\text {over }}$ is the only variable affecting the additional strain and displacements (elastic moduli are assumed to be constant during simulation), while in COMOSL, the initial strain is not zero i.e. $\varepsilon_{i, i j} \neq 0$, indicating the effects from matrix gravity and initial pore water pressure cannot be ignored, the simulated results are determined by not only the overpressure but the initial stress and pore pressure. These two kinds of initial condition are the main difference in algorithm between the two simulators.

We selected four observation points (OPs) for the comparisons of the overpressure changes. Two of the observation points are located in the centre of the reservoir, while the other two are positioned $10 \mathrm{~m}$ above the caprock-reservoir interface. Detailed positions of OPs are shown in Table 2 and

The comparison of the two simulators is further provided as breakthrough curves (plots of parameter of interest per time) at different observation points, and as plots of parameter of interest over horizontal planes at different depth.

Figure 2 presents the comparison of overpressures at $100 \mathrm{~m}(\mathrm{OPs} 1,3)$ and $1000 \mathrm{~m}(\mathrm{OPs} 2,4)$ away from the injection well, respectively. The overpressures show very good agreement during the whole simulation.
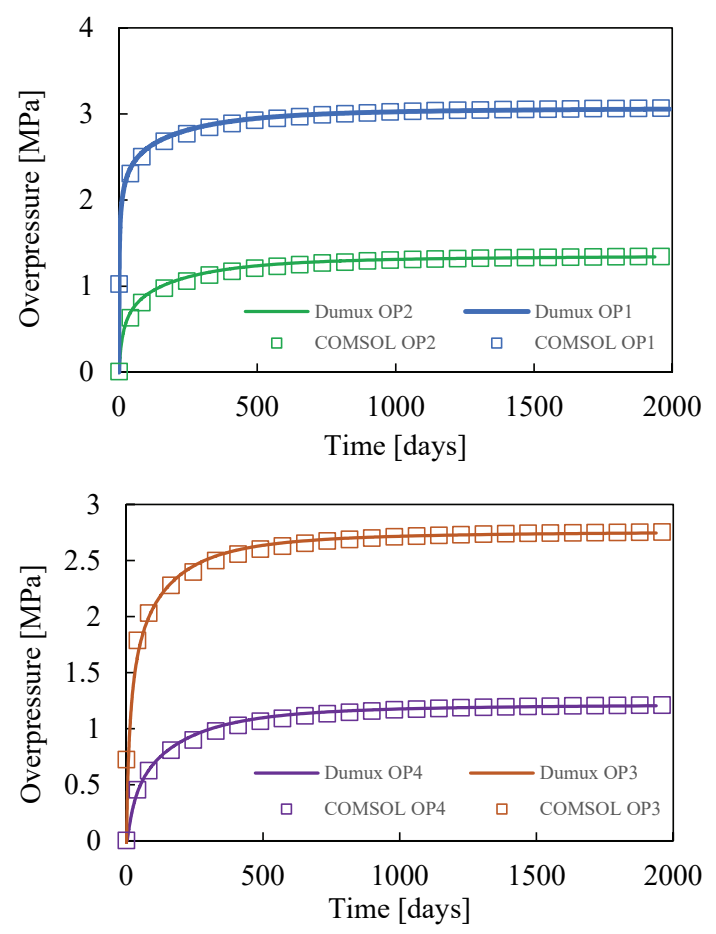

Figure 2. Overpressure comparison between $\operatorname{DuMu}^{\mathrm{x}}$ and COMSOL Multiphysics at different observation points.

\subsection{Displacement}

Another important variable considered for comparison is displacement obtained by Eq. (7). In $\mathrm{DuMu}^{\mathrm{X}}$, the simulated displacement is fully caused by the overpressure $\left(\varepsilon_{i, i j}=0\right.$ in Eq. (9)), while in COMSOL, stresses and overpressure are both the keys factor 
affecting the displacement $\left(\varepsilon_{i, i j} \neq 0\right.$ in Eq. (9)), for the comparison, the displacement presented below from COMSOL is the difference between the simulated results and initial displacement. The displacement is plotted over the interfaces of reservoir-caprock (RC) and caprockupper aquifer (CUA) at times 30 days, 365 days and 1000 days after the injection started.

Figure 3 shows the comparisons between modelled vertical displacements. It can be observed that the profiles as well as the values of these two models are very similar.

Like the comparison of overpressure, the vertical displacements show very good agreement. The displacement is maximum near the injection well and declines exponentially with the increasing distance from the well. The maximum simulated displacements amount to $0.036 \mathrm{~m}$ and $0.015 \mathrm{~m}$ at the CUA interface and $\mathrm{RC}$ interface respectively. Discrepancies are found in nearwellbore regions, which dissipate towards the model boundary. Discrepancies between displacements are larger at early than at late times. Furthermore, the discrepancies are more pronounced at the $\mathrm{RC}$ interface compared to the CUA interface.

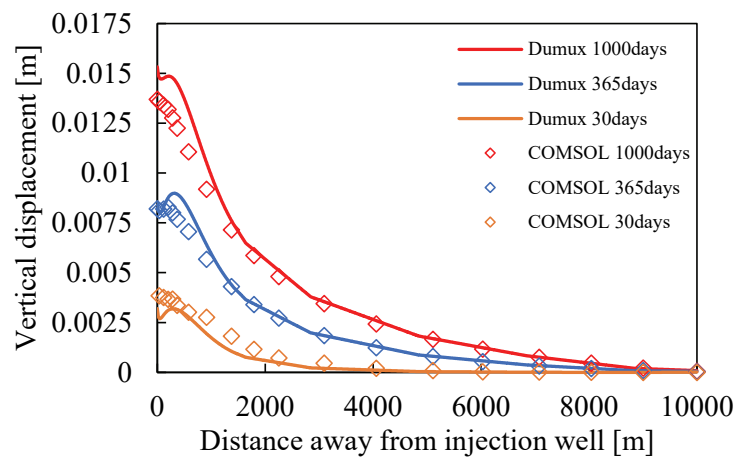

(a)

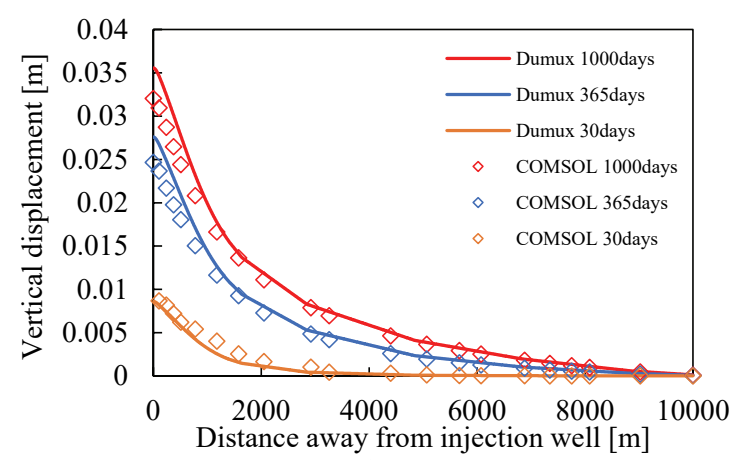

(b)

Figure 3. Displacement comparison between $\mathrm{DuMu}^{\mathrm{X}}$ and COMSOL Multiphysics. (a) RC interface (b) CUA interface

\subsection{Stress}

Temporal change in stress is assessed to investigate confidence of the two models.

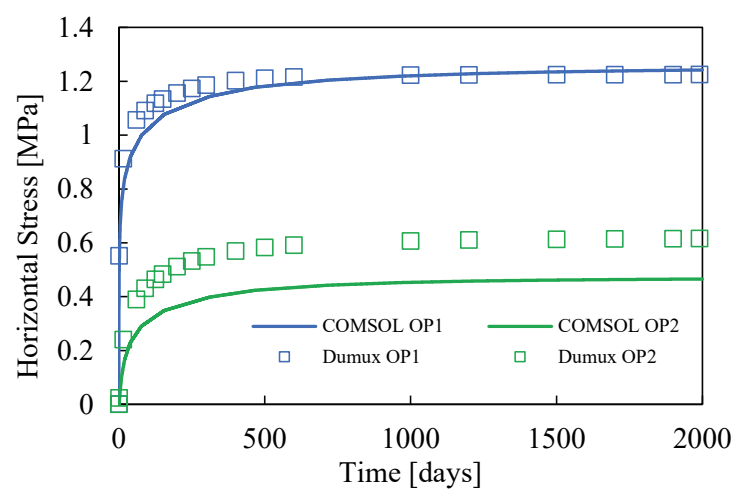

Figure 4. Horizontal stress change comparison between $\mathrm{DuMu}^{\mathrm{X}}$ and COMSOL Multiphysics at OP 1 and OP 2 .

Figure 4 presents the horizontal stress change over time for two OP locations. In OP $1, \mathrm{DuMu}^{\mathrm{x}}$ and COMSOL agree well. However, in OP 2, the stress change modelled by COMSOL is lower by $0.2 \mathrm{MPa}$ over the entire simulated period except at the beginning. The reason for the discrepancy is that, in $\mathrm{DuMu}^{\mathrm{X}}$, the water overpressure is the only variable affecting the simulation results aforementioned, the strains and displacements are calculated firstly by the simulator and then the stresses are calculated later by the simulated results i.e. strains, however, in COMSOL, the reference is the condition that the stress is zero, i.e. $\sigma_{i, i j}=0$, in this case, the influence from the initial stress and pore pressure need to be taken into consideration during the whole simulation, the strains are obtained by stresses and pore pressure, The opposite computation order leads to the large discrepancy in OP 2.

Table 2 Observation points

\begin{tabular}{|c|c|c|}
\hline & \multicolumn{2}{|c|}{ Distance away from injection well } \\
\hline Middle & OP 1 & OP 2 \\
Reservoir & $100 \mathrm{~m}$ & $1000 \mathrm{~m}$ \\
\hline $\mathbf{1 0}$ m above & OP 3 & OP 4 \\
Reservoir & $100 \mathrm{~m}$ & $1000 \mathrm{~m}$ \\
\hline
\end{tabular}

\section{Conclusion}

This paper provides a comparison study between two numerical simulators to model hydro-mechanical processes induced by fluid injection in a layered georeservoir. The simulators, $\mathrm{DuMu}^{\mathrm{X}}$ and COMSOL Multiphysics, are using different discretization schemes and are implemented in different frameworks.

A good agreement is obtained from the comparisons of water overpressure, displacement and horizontal stress change. This agreement increases the confidence in the reliability of these two hydro-mechanical simulators.

Benchmarking studies are useful to verify the reliability of models simulating multi-physics coupled processes. The more complex physical processes are involved, the less likely to find analytical solutions it becomes. At the same time, conducting experiments for achieving a model validation, is limited by increased technical complexity and cost. 
Generalisations based on a single benchmarking study using only two numerical simulators are limited. Different geometrical settings and boundary conditions, lead to differences between the simulated results. These differences can be considerably large. Therefore, further benchmarking studies are essential, and can be aimed to include higher geometrical complexity, or physical complexity, e.g. non-isothermal, multi-phase, etc. Numerical studies such as this one contribute to broaden the overall understanding of HM models and enhance the confidence in their ability to predict.

\section{References}

1. Beck M (2019) Conceptual approaches for the analysis of coupled hydraulic and geomechanical processes. $\mathrm{PhD}$ Thesis, Stuttgart University

2. Beck M, Class H (2019) Modelling fault reactivation with characteristic stress-drop terms. In: Advances in Geosciences. Copernicus GmbH, pp 1-7

3. Beck M, Seitz G, Class H (2016) Volume-Based Modelling of Fault Reactivation in Porous Media Using a ViscoElastic Proxy Model. Transp Porous Media 114:505-524 . https://doi.org/10.1007/s11242-016-0663-5

4. Berre I, Boon W, Flemisch B, Fumagalli A, Gläser D, Keilegavlen E, Scotti A, Stefansson I, Tatomir A (2018) Call for participation: Verification benchmarks for singlephase flow in three-dimensional fractured porous media. https://arxiv.org/abs/1809.06926

5. Berre I, Boon WM, Flemisch B, Fumagalli A, Glaser D, Keilegavlen E, Scotti A, Stefansson I, Brenner K, Burbulla S, Devloo P, Favino M, Hennicker J, Lee I-H, Masson R, Mosthaf K, Chiara MG, Ni C-F, Nikitin K, Schadle P, Svyatskiy D, Yanbarisov R, Zulian P (2020a) Verification benchmarks for single-phase flow in three-dimensional fractured porous media. Adv Water Resour Rev 51

6. Berre I, Boon WM, Flemisch B, Fumagalli A, Gläser D, Keilegavlen E, Scotti A, Stefansson I, Tatomir A, Brenner K, Burbulla S, Devloo P, Duran O, Favino M, Hennicker J, Lee I-H, Lipnikov K, Masson R, Mosthaf K, Nestola MGC, Ni C-F, Nikitin K, Schädle P, Svyatskiy D, Yanbarisov R, Zulian P (2020b) Verification benchmarks for single-phase flow in three-dimensional fractured porous media. ArXiv200207005 Cs Math

7. Class H, Ebigbo A, Helmig R, Dahle HK, Nordbotten JM, Celia MA, Audigane P, Darcis M, Ennis-King J, Fan Y, Flemisch B, Gasda SE, Jin M, Krug S, Labregere D, Naderi Beni A, Pawar RJ, Sbai A, Thomas SG, Trenty L, Wei L (2009) A benchmark study on problems related to CO2 storage in geologic formations : Summary and discussion of the results (Original paper). Comput Geosci 13:409-434

8. Darcis MY (2013) Coupling models of different complexity for the simulation of $\mathrm{CO} 2$ storage in deep saline aquifers. Heft 218. Ph. D Thesis, University of Stuttgart

9. Ebigbo A, Class H, Helmig R (2007) CO2 leakage through an abandoned well: problem-oriented benchmarks. Comput Geosci 11:103-115 . https://doi.org/10.1007/s10596-0069033-7

10. Figueiredo B, Tsang C-F, Niemi A (2020) The influence of coupled thermo-mechanical processes on the pres-sure and temperature due to cold water injection into multiple fracture zones in deep rock formation

11. Flemisch B, Berre I, Boon W, Fumagalli A, Schwenck N, Scotti A, Stefansson I, Tatomir A (2018) Benchmarks for single-phase flow in fractured porous media. Adv Water Resour 111:239-258

https://doi.org/10.1016/j.advwatres.2017.10.036

12. Flemisch B, Darcis M, Erbertseder K, Faigle B, Lauser A, Mosthaf K, Müthing S, Nuske P, Tatomir A, Wolff M, Helmig R (2011) DuMux: DUNE for multi\{phase, component, scale, physics, ... \} flow and transport in porous media. Adv Water Resour 34:1102-1112 . https://doi.org/10.1016/j.advwatres.2011.03.007

13. Gläser D, Dell'Oca A, Tatomir A, Bensabat J, Class H, Guadagnini A, Helmig R, McDermott C, Riva M, Sauter M (2016) An Approach Towards a FEP-based Model for Risk Assessment for Hydraulic Fracturing Operations. Energy Procedia 97:387-394 https://doi.org/10.1016/j.egypro.2016.10.030

14. Holzbecher E (2013) Coupled Hydro-Mechanical Modelling of Deep Geothermal Heat Production. In: Poromechanics V. American Society of Civil Engineers, Vienna, Austria, pp 1913-1922

15. Rutqvist, J., Rinaldi, A.P., Cappa, F., Moridis, G.J (2013) Modeling of fault reactivation and induced seismicity during hydraulic fracturing of shale-gas reservoirs. J. Petrol. Sci. Eng. 107, 31-44

16. Schout G, Hartog N, Hassanizadeh SM, Helmig R, Griffioen J (2020) Impact of groundwater flow on methane gas migration and retention in unconsolidated aquifers. $\mathrm{J}$ $\begin{array}{lll}\text { Contam Hydrol 230:103619 } & \end{array}$ https://doi.org/10.1016/j.jconhyd.2020.103619

17. Tatomir A, Dimache A-N, Iulian I, Sauter M (2019) Modelling of $\mathrm{CO} 2$ storage in geological formations with DuMux, a free-open-source numerical framework. A possible tool to assess geological storage of carbon dioxide in Romania. E3S Web Conf 85:07002 https://doi.org/10.1051/e3sconf/20198507002

18. Tatomir A, McDermott C, Bensabat J, Class H, Edlmann K, Taherdangkoo R, Sauter M (2018) Conceptual model development using a generic Features, Events, and Processes (FEP) database for assessing the potential impact of hydraulic fracturing on groundwater aquifers. Adv Geosci 45:185-192 . https://doi.org/10.5194/adgeo-45185-2018

19. Tatomir AB, Tomac I, Sauter M (2016) A Parametric Sensitivity Study on CO2 Injection in Deep Saline Aquifers Accounting for Hydro-mechanical Microfracturing. Kiel, Germany, pp 223-230

20. Tony T. Freeman, Rick J. Chalaturnyk, Igor I. Bogdanov (2008) Fully Coupled Thermo-Hydro-Mechanical Modeling by COMSOL Multiphysics, with Applications in Reservoir Geomechanical Characterization, COMSOL Conference 2008 Boston

21. Vilarrasa V, Tatomir A, Tian L, Levchenko S, Basirat F, Carrera J, Niemi A, Sauter M (2020) Code comparison of coupled thermo-hydro-mechanical processes induced by cold $\mathrm{CO} 2$ injection in deep saline aquifers (in preparation)

22. Xiang Sun, Hao Luo (2018) A coupled thermal- hydraulicmechanical- chemical (THMC) model for methane hydrate bearing sediments using COMSOL Multiphysics. Journal of Zhejiang University-SCIENCE, A volume 19, pages 600-623 